\title{
Microstructure Evolution of a Ternary Monotectic Alloy During Directional Solidification
}

\author{
Shu Chen $\cdot$ Jiu-Zhou Zhao $\cdot$ Hong-Xiang Jiang $\cdot$ Jie He
}

Received: 27 May 2014/Revised: 26 September 2014/Published online: 10 January 2015

(C) The Chinese Society for Metals and Springer-Verlag Berlin Heidelberg 2015

\begin{abstract}
A model was developed to describe the microstructure evolution in a directionally solidified ternary monotectic alloy. The directional solidification experiments were carried out on $\mathrm{Al}-3 \mathrm{~Pb}-1 \mathrm{Sn}$ (wt\%) alloys by using a Bridgman apparatus. The microstructure evolution in the directionally solidified sample was calculated. The numerical results agree well with the experimental ones. It is demonstrated that the nucleation of the minority phase droplets occur at two different positions. One corresponds to the liquid-liquid decomposition, which occurs in front of the solidification interface. The other is at the liquid/solid interface. The nucleation rate of the minority phase droplets at the liquid/solid interface is significantly higher than at the position in front of the solidification interface. The characteristic of the nucleation process leads to a bimodal size distribution of the minority particles in the directionally solidified sample.
\end{abstract}

KEY WORDS: Ternary monotectic alloy; Directional solidification; Modeling

\section{Introduction}

Monotectic alloys are characterized by the existence of a miscibility gap in the liquid state. When a liquid is cooled into the miscibility gap, the components of the alloy become immiscible and two liquid phases develop [1]. Generally, the liquid-liquid decomposition begins with the nucleation of the liquid minority phase in the form of droplets. The minority phase droplets (MPDs) grow in the liquid matrix. They also settle due to gravity [2-5] and migrate due to a temperature gradient or a concentration gradient [1]. The microstructure evolution during the liquid-liquid decomposition is a result of the combined action of all these factors [1]. For a ternary monotectic alloy, when cooled below the temperature of miscibility

Available online at http://link.springer.com/journal/40195

S. Chen · J.-Z. Zhao $(\bowtie) \cdot$ H.-X. Jiang $\cdot$ J. He

Institute of Metal Research, Chinese Academy of Sciences,

Shenyang 110016, China

e-mail: jzzhao@imr.ac.cn gap, the matrix liquid begins to solidify. During the solidification of the matrix liquid, the solutes are expelled in front of the solidification interface. The nucleation of the MPDs may occur in the melt next to the solidification interface if the local enrichment of solutes is high enough. In comparison with the binary monotectic alloys, the solidification process of the ternary monotectic alloys is far more complex. In the last decades, most of the studies focused on the binary monotectic alloys [6-11].

Great progress has been made on the investigation of the microstructure formation during cooling a binary alloy in the miscibility gap. But, up to date, little is known of the solidification process of ternary monotectic alloys in details. The microstructure evolution during cooling a ternary or a multi-component immiscible alloy remains a scientific problem to be resolved. Directional solidification experiments have been carried out with $\mathrm{Al}-\mathrm{Pb}-\mathrm{Sn}$ alloys, which have great potential to be used as bearing materials. A model is proposed to describe the microstructure evolution under the conditions of directional solidification. The model is verified by comparing with the experimental results and applied to investigate the kinetic details of the 
microstructure evolution in the directionally solidified Al$\mathrm{Pb}-\mathrm{Sn}$ alloys.

\section{Theoretical Approach}

\subsection{Population Dynamics Model}

The microstructure evolution in front of the solid/liquid interface can be described by a droplet radius distribution function $f(R, r, z, t)$; it is so defined that $f(R, r, z, t) \mathrm{d} R$ gives the number of MPDs per unit volume at position $(r, z)$ and time $t$ in a size class from $R$ to $R+\mathrm{d} R$. It obeys the following equation during solidification [9]:

$\frac{\partial f}{\partial t}+\nabla \cdot\left[\left(\boldsymbol{u}_{\mathrm{M}}+\boldsymbol{u}_{\mathrm{S}}+\boldsymbol{V}\right) f\right]+\frac{\partial}{\partial R}(v f)=\left.\frac{\partial I}{\partial R}\right|_{R=R_{\mathrm{C}}}$,

$I=N_{0} \cdot O \cdot \Gamma \cdot Z \cdot \exp \left(-\frac{\Delta G_{\mathrm{C}}}{k_{\mathrm{B}} T}\right)$,

where $\boldsymbol{u}_{\mathrm{M}}$ is the Marangoni velocity of the MPD. $\boldsymbol{u}_{\mathrm{S}}$ is the Stokes velocity of the MPD. The alloy solidifies at the rate of $\boldsymbol{V} . I$ is the nucleation rate of the MPDs [12], $N_{0}=\left(x_{\mathrm{A}} \Omega_{\mathrm{A}}+x_{\mathrm{B}} \Omega_{\mathrm{B}}+x_{\mathrm{C}} \Omega_{\mathrm{C}}\right)^{-1}, \quad O=4 n_{\mathrm{c}}^{2 / 3}, \quad \Gamma=6 D / \lambda^{2}$, $Z=\left[\Delta G_{\mathrm{C}} /\left(3 \pi k_{\mathrm{B}} T n_{\mathrm{c}}^{2}\right)\right]^{1 / 2}, \Delta G_{\mathrm{C}}=16 \pi \sigma^{3} /\left(3 \Delta G_{V}^{2}\right) . \Omega_{\mathrm{A}}, \Omega_{\mathrm{B}}$ and $\Omega_{\mathrm{C}}$ are the atomic volumes of the component $\mathrm{A}, \mathrm{B}$ and $\mathrm{C}$, respectively. $x_{\mathrm{A}}, x_{\mathrm{B}}$ and $x_{\mathrm{C}}$ are the mole fractions of the component $\mathrm{A}, \mathrm{B}$ and $\mathrm{C}$, respectively. $n_{\mathrm{c}}$ is the number of atoms in a MPD of the critical nucleus radius. $\lambda$ is the average jump distance of the atoms due to diffusion. $k_{\mathrm{B}}$ is Boltzmann's constant. $\sigma$ is the interfacial energy between the two liquids. $\Delta G_{V}=\Delta G \cdot V_{\mathrm{mol}}^{-1}$ is the gain in the free energy per unit volume on nucleation. $\Delta G$ is the molar Gibbs free energy change due to the liquid-liquid phase transformation. $V_{\mathrm{mol}}$ is the molar volume of the MPDs. $v$ is the diffusional growth rate of the MPDs.

The diffusional growth rate can be calculated by $[13$, 14]:

$v=\frac{\mathrm{d} R}{\mathrm{~d} t}=D_{i} \frac{C_{i}^{\mathrm{m}}-C_{i}^{I}}{C_{i}^{\beta}-C_{i}^{I}} \frac{1}{R}+\frac{R}{3} \frac{\frac{\mathrm{d} C_{i}^{\beta}}{\mathrm{d} T} \frac{\mathrm{d} T}{\mathrm{~d} t}}{C_{i}^{\beta}-C_{i}^{I}}$,

where the subscript $i$ stands for component $\mathrm{Pb}$ or $\mathrm{Sn} . C_{i}^{\mathrm{m}}$ is the mean field concentration of the matrix liquid. $C_{i}^{\beta}$ is the concentration of the liquid within the MPD. $C_{i}^{I}=$ $C_{i}^{\infty} \exp \left(\alpha_{\mathrm{S}} / R\right)$ is the concentration of the solute in the matrix at the interphase boundary. $C_{i}^{\infty}$ is the equilibrium composition at a flat interface boundary. $\alpha_{\mathrm{S}}=2 \sigma \Omega^{\beta} / k_{\mathrm{B}} T$ is the capillary length. $\Omega^{\beta}$ is the atomic volume of the MPDs. $D_{i}$ is diffusion coefficient. Considering that $\mathrm{Sn}$ has a relatively larger diffusivity compared with $\mathrm{Pb}$, we assume in the calculations that the growth of the droplets is controlled by the diffusional transfer of $\mathrm{Pb}$.

\subsection{Energy Conservation Equation}

The temperature field of the sample during solidification can be calculated by

$\frac{\partial\left(\rho^{\text {mix }} C_{p}^{\text {mix }} T\right)}{\partial t}+\nabla \cdot\left(\mathbf{V} \rho^{\text {mix }} C_{p}^{\text {mix }} T\right)=\nabla\left(k^{\text {mix }} \nabla T\right)+q_{\mathrm{S} / \mathrm{L}}$,

where $C_{p}^{\operatorname{mix}}$ is the specific heat of the alloy, $\rho^{\operatorname{mix}}$ is the density of the alloy, $k^{\text {mix }}$ is the thermal conductivity of the alloy, $q_{\mathrm{S} / \mathrm{L}}$ is the latent heat released at the solidification interface.

\subsection{Concentration Conservation Equation}

The solute transfers by the diffusion of the solute in the matrix and the motions of the MPDs. The concentration field in front of the solidification interface can be obtained by solving the following partial differential equation:

$$
\begin{aligned}
& \frac{\partial C_{i}^{\mathrm{mix}}}{\partial t}+\nabla \cdot\left(C_{i}^{\mathrm{m}} \boldsymbol{V}\right)=\nabla^{2}\left[D_{i} S_{i}(1-\varphi)\right] \\
& -\frac{4 \pi}{3} \nabla \cdot\left\{\int_{0}^{\infty}\left[\left(\boldsymbol{u}_{\mathrm{M}}+\boldsymbol{u}_{\mathrm{S}}+\boldsymbol{V}\right) f\left(C_{i}^{\beta}-C_{i}^{\mathrm{m}}\right) R^{3} \mathrm{~d} R\right]\right\},
\end{aligned}
$$

where the subscript $i$ stands for component $\mathrm{Pb}$ or $\mathrm{Sn} . S_{i}=$ $C_{i}^{\mathrm{m}}-{ }^{\infty} C_{i}^{\mathrm{m}}$ is the supersaturation, ${ }^{\infty} C_{i}^{\mathrm{m}}$ is the equilibrium composition of the matrix liquid. $C_{i}^{\operatorname{mix}}$ is the content of the solute $i$ in the local mixture of liquids.

\section{Results and Discussion}

\subsection{Directional Solidification Experiments and Validity of the Model}

Directional solidification experiments were carried out on Al-3 wt $\%$ Pb-1 wt\% Sn alloy by using a Bridgman-type solidification apparatus. The alloy was prepared by using pure $\mathrm{Al}$ (99.99 wt\%), $\mathrm{Pb}$ (99.99 wt\%) and $\mathrm{Sn}(99.99 \mathrm{wt} \%)$. The raw materials were molten in a cylindrical graphite crucible first. The melt was then heated to $1,173 \mathrm{~K}$ and held the temperature for $30 \mathrm{~min}$ to form a single-phase homogeneous liquid. At last, the crucible was withdrawn into a bath of a Ga-In-Sn liquid alloy. The samples are $6 \mathrm{~mm}$ in diameter and $150 \mathrm{~mm}$ in length. They were cut longitudinally to prepare the metallographic specimens. The microstructure images were taken by using a scanning electron microscope in the back-scattered mode.

Figure 1 shows the microstructure of the $\mathrm{Al}-3 \mathrm{~Pb}-1 \mathrm{Sn}$ monotectic alloys solidified directionally at different rates. The white $(\mathrm{Pb}, \mathrm{Sn})$-rich minority phase particles are 

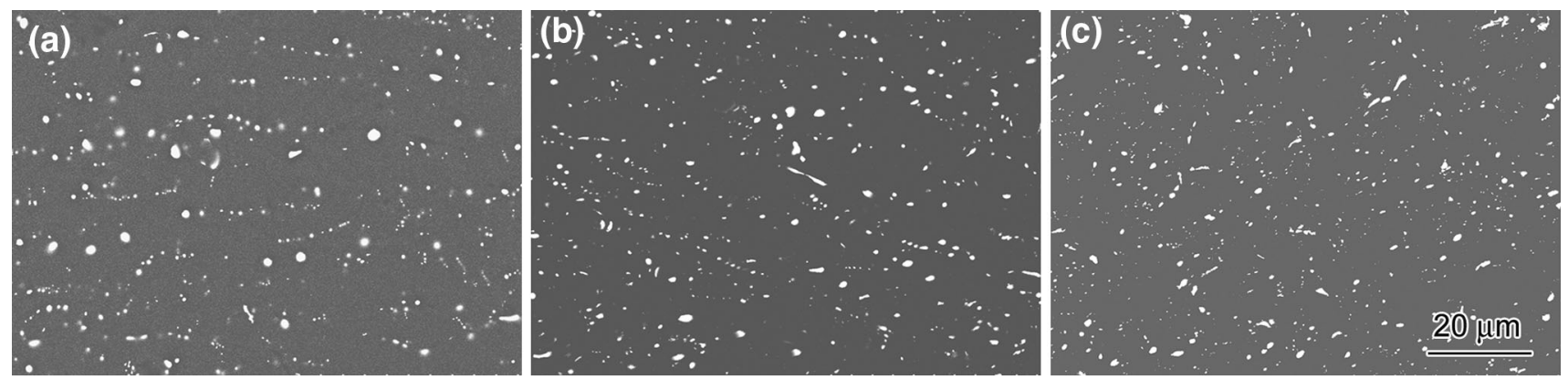

Fig. 1 Microstructures of the Al-3 wt $\% \mathrm{~Pb}-1 \mathrm{wt} \% \mathrm{Sn}$ alloys directionally solidified at different solidification rates: a $2 \mathrm{~mm} / \mathrm{s}, \mathbf{b} 5 \mathrm{~mm} / \mathrm{s}$, c $8 \mathrm{~mm} / \mathrm{s}$

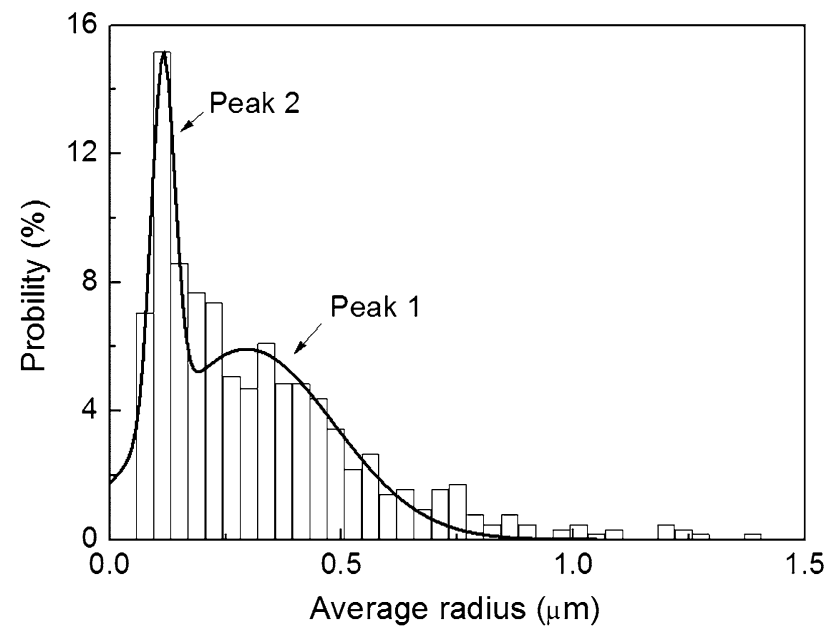

Fig. 2 Size distribution of the ( $\mathrm{Pb}, \mathrm{Sn})$-rich particles in the $\mathrm{Al}-3 \mathrm{~Pb}-$ $1 \mathrm{Sn}$ alloy directionally solidified at the rate of $5 \mathrm{~mm} / \mathrm{s}$

dispersed homogeneously in the dark Al-rich matrix phase. The size distribution of $(\mathrm{Pb}, \mathrm{Sn})$-rich particles in the alloy solidified at the rate of $5 \mathrm{~mm} / \mathrm{s}$ is shown in Fig. 2. It is characterized by two peaks (peak 1 and peak 2). Peak 2 corresponds to the $(\mathrm{Pb}, \mathrm{Sn})$-rich particles/droplets produced due to the monotectic reaction during cooling the alloy in the liquid-liquid-solid three-phase regions. These droplets nucleate at or in a region near the $\mathrm{S} / \mathrm{L}$ interface. They are engulfed by the $S / L$ interface almost immediately after nucleation and thus achieve a smaller size. Peak 1 corresponds to the $(\mathrm{Pb}, \mathrm{Sn})$-rich particles/droplets produced due to the liquid-liquid decomposition. These droplets nucleate in front of S/L interface. They have some time to grow before they were engulfed by the S/L interface and thus achieve a big size. Table 1 gives the 3D average radius of the $(\mathrm{Pb}, \mathrm{Sn})$-rich particles. It indicates that the average size of the $(\mathrm{Pb}, \mathrm{Sn})$-rich particles decreases with the increase in the solidification rate.

Calculations were carried out to simulate the microstructure evolution during solidification. The phase
Table 1 Average radius of the $(\mathrm{Pb}, \mathrm{Sn})$-rich particles in the Al-3 $\mathrm{wt} \% \mathrm{~Pb}-1 \mathrm{wt} \% \mathrm{Sn}$ alloys solidified directionally at different solidification rates

\begin{tabular}{ll}
\hline $\begin{array}{l}\text { Solidification rates } \\
(\mathrm{mm} / \mathrm{s})\end{array}$ & $\begin{array}{l}\text { 3D average } \\
\text { radius }(\mu \mathrm{m})\end{array}$ \\
\hline 2 & 0.43 \\
5 & 0.34 \\
8 & 0.26 \\
\hline
\end{tabular}

diagram of $\mathrm{Al}-\mathrm{Pb}-\mathrm{Sn}$ alloy was calculated directly from the Gibbs free energy functions given by literatures [1517]. The Gibbs free energies of the pure components are taken from the SGTE (Scientific Group Thermodata Europe) database compiled by Dinsdale [18]. The interfacial energy between the two liquid phases in the miscibility gap satisfies $[19,20]$ :

$\sigma=\sigma_{0} \cdot\left(1-T / T_{\mathrm{C}}\right)^{\delta}$,

where $T_{\mathrm{C}}$ is the critical temperature of the immiscible system. $\sigma_{0}$ and $\delta$ are constants. Calculation demonstrates that the critical temperature $T_{\mathrm{C}}$ of the ternary $\mathrm{Al}-\mathrm{Pb}-\mathrm{Sn}$ system equals $1,695 \mathrm{~K}$. In this study, $\delta$ is taken as 1.217 [21]. The only unknown parameter is $\sigma_{0}$. The calculation demonstrates that the calculated average radius of the minority phase particles agrees well with the experimental one when $\sigma_{0}$ equals $280 \mathrm{mN} / \mathrm{m} . \sigma_{0}$ is thus taken as $280 \mathrm{mN} / \mathrm{m}$.

The dynamic viscosities of the Al-rich matrix liquid and the MPD are taken as the corresponding values for the pure $\mathrm{Al}$ [22] and $\mathrm{Pb}$ [23], respectively:

$\mu_{\mathrm{m}}=10^{-4.3} \mathrm{e}^{3.34 T_{\mathrm{L}} /\left(T-0.25 T_{\mathrm{L}}\right)}$,
$\mu_{\beta}=4.636 \times 10^{-4} \mathrm{e}^{1036.7 / T}$.

The self-diffusion coefficient of $\mathrm{Al}$ is calculated from the dynamic viscosity of Al by using the Stokes-Einstein relation [24]: 
$D^{\mathrm{Al}}=\frac{k_{\mathrm{B}} T}{6 \pi \mu_{\mathrm{m}} r_{\mathrm{Al}}}$.

The diffusivity of solute $i$ in liquid $\mathrm{Al}$ is calculated by $[25,26]$ :

$D^{i}=\frac{r_{\mathrm{Al}}}{r_{i}} D^{\mathrm{Al}}=\frac{k_{\mathrm{B}} T}{6 \pi \mu_{\mathrm{m}} r_{i}}$,

where $r_{i}$ is the ionic radius of element $i . r_{\mathrm{Pb}}=0.065 \mathrm{~nm}$ and $r_{\mathrm{Sn}}=0.055 \mathrm{~nm}$.

The measured and calculated temperature profiles of the melt in front of solidification interface are shown in Fig. 3. The calculated $3 \mathrm{D}$ average radius of the $(\mathrm{Pb}, \mathrm{Sn})$-rich particles in the samples solidified at different rates is shown in Fig. 4. It demonstrates that a higher solidification rate leads to a higher cooling rate and thus a smaller average

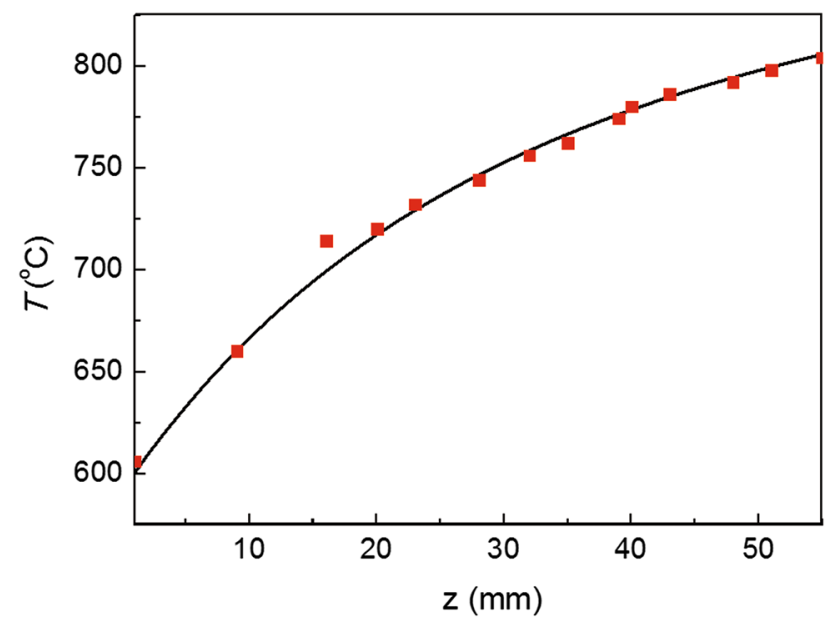

Fig. 3 Measured (squares) and calculated (solid line) temperature profile of the melt in front of the solidification interface along the central $z$ axes of the sample

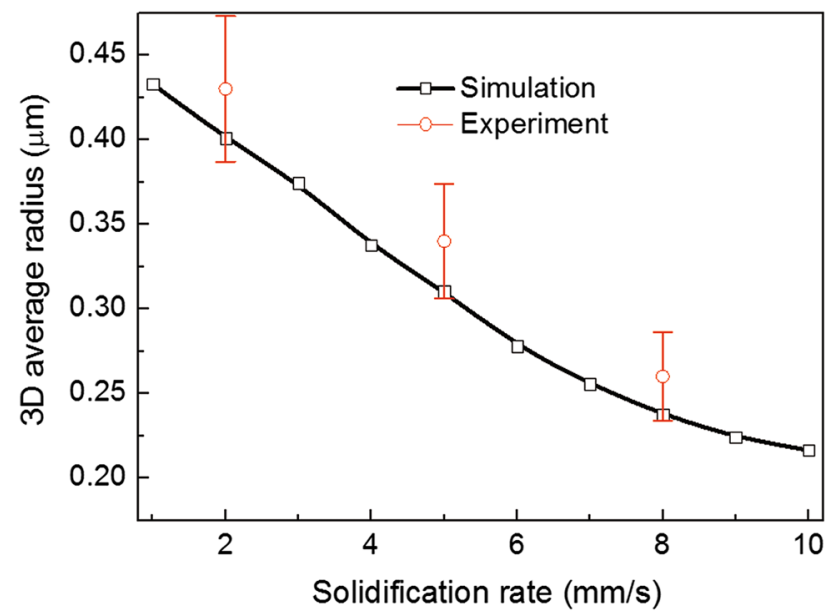

Fig. 4 Average radius of the ( $\mathrm{Pb}, \mathrm{Sn})$-rich particles in the Al-3 wt\% $\mathrm{Pb}-1 \mathrm{wt} \% \mathrm{Sn}$ alloy directionally solidified at different solidification rates radius of the minority phase particles. The favorable agreement between the experimental and numerical results indicates that the microstructure evolution process can be described by the proposed model.

\subsection{Microstructure Evolution During the Liquid- Liquid Decomposition}

The calculated $\mathrm{Al}-\mathrm{Pb}-\mathrm{Sn}$ phase diagram is shown in Fig. 5. It demonstrates that the binodal line temperature ( $\left.T_{\text {immiscible }}\right)$ for $\mathrm{Al}-3 \mathrm{wt} \% \mathrm{~Pb}-1 \mathrm{wt} \% \mathrm{Sn}$ alloy is $768.5^{\circ} \mathrm{C}$. When cooling the alloy above $T_{\text {immiscible }}$, the alloy is in a superheated state and remains as a homogeneous singlephase liquid. No phase transformations occur and the composition of the melt remains constant. When the temperature drops to a temperature below $T_{\text {immiscible }}$, the melt becomes supersaturated and tends to transform into two liquids. The liquid-liquid phase transformation begins with

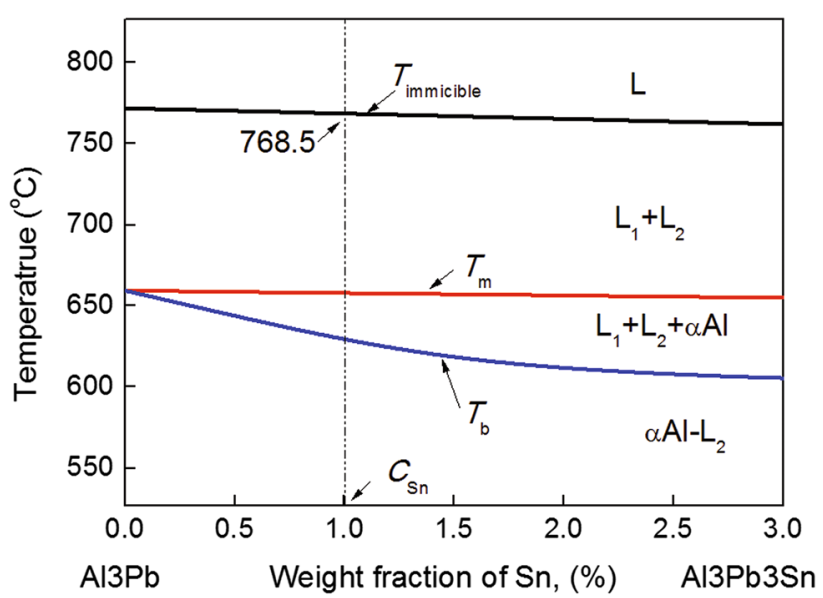

Fig. 5 Vertical cross-sectional phase diagram for $\mathrm{Al}-3 \mathrm{~Pb}-x \mathrm{Sn}$ ternary alloys

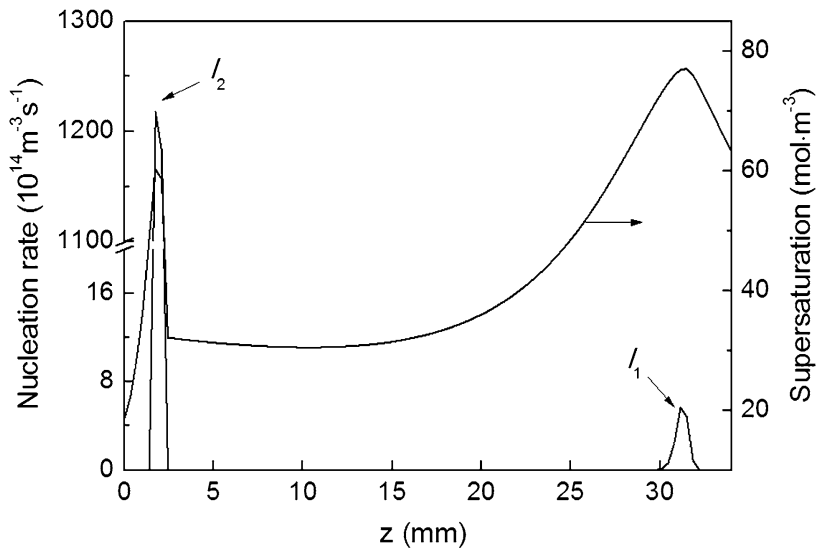

Fig. 6 Supersaturation of the matrix melt and nucleation rate of the MPDs along the central $z$ axes of the sample directionally solidified at the rate of $5 \mathrm{~mm} / \mathrm{s}$ 
the nucleation of the $(\mathrm{Pb}, \mathrm{Sn})$-rich MPDs (the first nucleation peak of the MPDs as shown in Fig. 6). Since this moment, the supersaturation of the matrix melt is determined by the concurrent actions of the drop in melt temperature as well as the nucleation and diffusional growth of the MPDs. The drop in the melt temperature tends to increase the supersaturation, while the nucleation and diffusional growth of the MPDs tend to reduce the supersaturation. In the early stage of the liquid-liquid decomposition, the supersaturation increases with time because both the nucleation rate and the number density of the MPDs (the number of MPDs per unit volume) are very low. The increase in the supersaturation leads to a rapid rise in the nucleation rate and number density of the MPDs. As a result, the rate at which the nucleation and growth of the MPDs consume $\mathrm{Pb}$ and $\mathrm{Sn}$ increases, and the supersaturation decreases quickly. Soon the nucleation ceases. During the nucleation period of the MPDs, the average radius of the $(\mathrm{Pb}, \mathrm{Sn})$-rich droplets increases relatively slowly because the small droplets are created continuously at a high rate. After the nucleation of the MPDs, the average radius of the $(\mathrm{Pb}, \mathrm{Sn})$-rich droplets increases rapidly due to the high level of the supersaturation. The growth rate slows down gradually due to the decrease in the supersaturation, as shown in the Figs. 6 and 7.

\subsection{Microstructure Evolution during Cooling in the Liquid-Liquid-Solid Three-Phase Region}

When the $\mathrm{Al}-3 \mathrm{~Pb}-1 \mathrm{Sn}$ alloy is cooled to the liquid-liquidsolid three-phase region, the precipitation of the solid $\alpha-A l$ begins. The solutes of $\mathrm{Pb}$ and $\mathrm{Sn}$ are expelled to the melt in front of the $\mathrm{S} / \mathrm{L}$ interface. The enrichment of the $\mathrm{Pb}$ and $\mathrm{Sn}$ causes a quick increase in the supersaturation of the local matrix melt. The nucleation of the MPDs thus occurs once again (the second nucleation peak of MPDs as shown in Fig. 6). $I_{2}$ is much higher than $I_{1}$. It causes a rapid increase

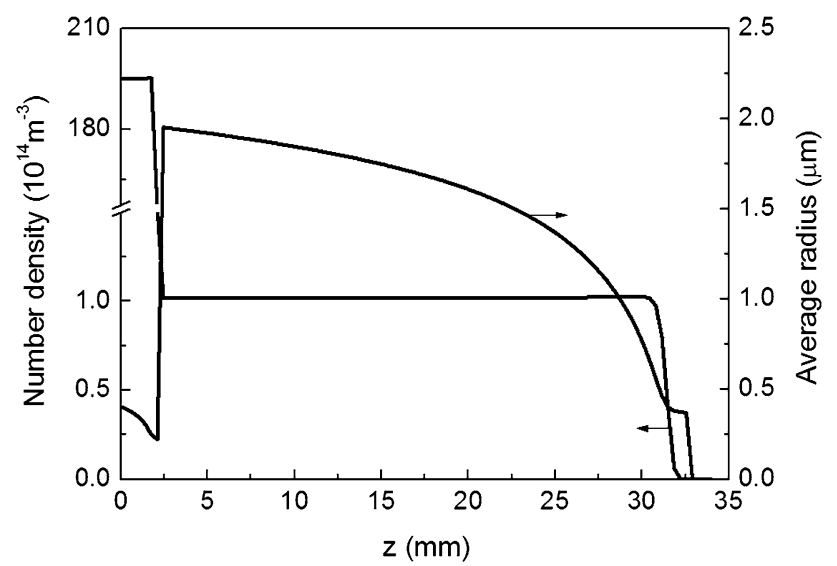

Fig. 7 Number density and average radius of the MPDs along the central $z$ axes of the sample solidified at the rate of $5 \mathrm{~mm} / \mathrm{s}$ in the number density of the MPDs and quick decrease in the average radius of the MPDs, as shown in Fig. 7.

\subsection{Effects of Solidification Rate on the Microstructure Evolution}

The microstructure evolution in the $\mathrm{Al}-3 \mathrm{wt} \% \mathrm{~Pb}-1 \mathrm{wt} \% \mathrm{Sn}$ sample directionally solidified at different rate is calculated. It is demonstrated that a higher solidification rate achieves a higher cooling rate. For the MPDs nucleated during the liquid-liquid decomposition, the higher the cooling rate is, the shorter the time period they cost to pass through the liquid-liquid and the liquid-liquid-solid phase temperature range is, the smaller the size it can achieve before they are engulfed by the S/L interface is. While for the MPDs nucleated during cooling in the liquid-liquidsolid three-phase region, the solidification rate has a weak effect on their sizes due to the fact that they are engulfed by the $\mathrm{S} / \mathrm{L}$ interface soon after their nucleation. As a result, the average radius of all minority phase particles decreases with the solidification rates, as shown in Fig. 4.

\section{Conclusions}

Directional solidification experiments were carried out on the $\mathrm{Al}-\mathrm{Pb}-\mathrm{Sn}$ ternary monotectic alloys. The directional solidified samples show a well-dispersed microstructure. The average radius of the $(\mathrm{Pb}, \mathrm{Sn})$-rich particles decreases with the increase of the solidification rate. A model describing the directional solidification process of the ternary immiscible alloy is developed. The microstructure evolution in directionally solidified $\mathrm{Al}-\mathrm{Pb}-\mathrm{Sn}$ ternary alloys is simulated by coupling the thermodynamic and kinetic calculations. The numerical results show that the microstructure evolution is a result of the concurrent action of the nucleation, diffusional growth and the motions of the MPDs. When solidifying an Al$3 \mathrm{~Pb}-1 \mathrm{Sn}$ alloy directionally, the nucleation of the MPDs occurs at two different positions. The nucleation of the MPDs due to the liquid-liquid decomposition occurs in front of the solidification interface. The nucleation of the MPDs due to the liquid-liquid-solid phase transformation occurs at the solid/ liquid interface. The numerical results show a favorable agreement with the experimental ones.

Acknowledgments This work was supported by the National Natural Science Foundation of China (Nos. 51471173, 51271185 and 51031003) and China Manned Space Engineering.

\section{References}

[1] J.Z. Zhao, Scr. Mater. 54, 247 (2006)

[2] T. Carlberg, H. Fredriksson, Metall. Trans. A 11, 1665 (1980) 
[3] L. Granasy, L. Ratke, Scr. Mater. 28, 1329 (1993)

[4] W.K. Thieringer, L. Ratke, Acta Metall. 35, 1237 (1987)

[5] R.B. Heady, J.W. Cahn, J. Chem. Phys. 58, 896 (1973)

[6] C.P. Wang, X.J. Liu, I. Ohnuma, R. Kainuma, K. Ishida, J. Phase Equilib. 23, 236 (2002)

[7] J.J. Guo, C.Z. Zhao, S.P. Wu, Y.Q. Su, J. Jia, Mater. Sci. Technol. 20, 653 (2004)

[8] X.Y. Lu, C.D. Cao, M. Kolbe, B. Wei, D.M. Herlach, Mater. Sci. Eng., A 375-377, 1101 (2004)

[9] J.Z. Zhao, Mater. Sci. Eng., A 454-455, 637 (2007)

[10] B.C. Luo, H.P. Wang, B.B. Wei, Chin. Sci. Bull. 54, 183 (2009)

[11] J.Z. Zhao, H.L. Li, L. Zhao, Acta Metall. Sin. 45, 1435 (2009) (in Chinese)

[12] J. Christian, The Theory of Phase Transformation in Metals and Alloys, 2nd edn. (Pergamon Press, New York, 1975), pp. 1-44

[13] J.Z. Zhao, L. Ratke, B. Feuerbacher, Modell. Simul. Mater. Sci. Eng. 6, 123 (1998)

[14] J.A. Marqusee, J. Ross, J. Chem. Phys. 80, 536 (1984)

[15] H.L. Lukas, S.G. Fries, B. Sundman, Computational Thermodynamics: The Calphad Method (Cambridge University Press, Cambridge, 2007), pp. 101-106
[16] J.H. Shim, H.N. Lee, H.P. Ha, Y.W. Cho, E.P. Yoon, J. Alloys Compd. 327, 270 (2001)

[17] O. Redlich, A.T. Kister, Ind. Eng. Chem. 40, 345 (1948)

[18] A.T. Dinsdale, Calphad 15, 317 (1991)

[19] N. Eustathopoulos, D. Chatain, C. Vahlas, Scr. Metall. 18, 1 (1984)

[20] L. Ratke, Immiscible Liquid Metals and Organics (DGMInformationsgesellschaft, Oberursel, 1993)

[21] M. Merkwitz, W. Hoyer, Z. Metallkd. 90, 363 (1999)

[22] C.V. Thompson, F. Spaepen, Acta Metall. 31, 2021 (1983)

[23] S.Z. Beer, Liquid Metals (Marcel Dekker Inc, New York, 1972), p. 415

[24] A.I. Pommrich, A. Meyer, D. Holland-Moritz, T. Unruh, Appl. Phys. Lett. 92, 241922 (2008)

[25] A.K. Roy, R.P. Chhabra, Metall. Trans. A 19, 273 (1988)

[26] X.P. Su, S. Yang, J.H. Wang, N.-Y. Tang, F.C. Yin, Z. Li, M.X. Zhao, J. Phase Equilib. Diffus. 31, 333 (2010) 